\title{
CNTs/ferrihydrite as a highly efficient heterogeneous Fenton catalyst: the important role of CNTs in accelerating $\mathrm{Fe}(\mathrm{III}) / \mathrm{Fe}$ (II) cycling
}

\author{
YANPING ZHU ${ }^{1}$, RUNLIANG ZHU ${ }^{1 *}$
}

${ }^{1}$ Guangzhou Institute of Geochemistry, Chinese Academy of Sciences (CAS), Guangzhou 510640, China

The generation of $\mathrm{Fe}(\mathrm{II})$ from $\mathrm{Fe}(\mathrm{III})$ is the rate-limiting step in the heterogeneous Fenton reaction, and accelerating this step is critical for enhancing the reaction efficiency and also the subject of extensive studies [1,2]. The strategies for accelerating the generation of $\mathrm{Fe}(\mathrm{II})$, therefore, are drawing particular concerns $[3,4]$.

In this work, the oxidized multi-walled carbon nanotubes (CNTs) were coupled with ferrihydrite $(\mathrm{Fh})$ to synthesize novel and highly efficient heterogeneous Fenton catalysts $(\mathrm{CNTs} / \mathrm{Fh})$, and the underlying mechanism were well explored. Interestingly, the calculated apparent rate constants by $3 \% \mathrm{CNTs} / \mathrm{Fh}$ could reach $\sim 7.1$ times as high as that by $\mathrm{Fh}$ (Fig. 1a), well in agreement with the accelerated decomposition rate of $\mathrm{H}_{2} \mathrm{O}_{2}$, as well as the enhanced generation rate of $\mathrm{Fe}(\mathrm{II})$ and hydroxyl radicals in the CNTs/Fh system.

The density functional theory calculations and the cyclic voltammograms curves both well indicated that the $\mathrm{Fe}(\mathrm{III}) / \mathrm{Fe}(\mathrm{II})$ redox cycling on $\mathrm{CNTs} / \mathrm{Fh}$ could be significantly enhanced during the Fenton reaction, from both dynamic (accelerating the electron transfer from $\mathrm{H}_{2} \mathrm{O}_{2}$ to $\mathrm{Fh}$ ) and thermodynamic (lowering $\mathrm{Fe}(\mathrm{III}) / \mathrm{Fe}$ (II) redox potential) aspects (Fig. 1b).
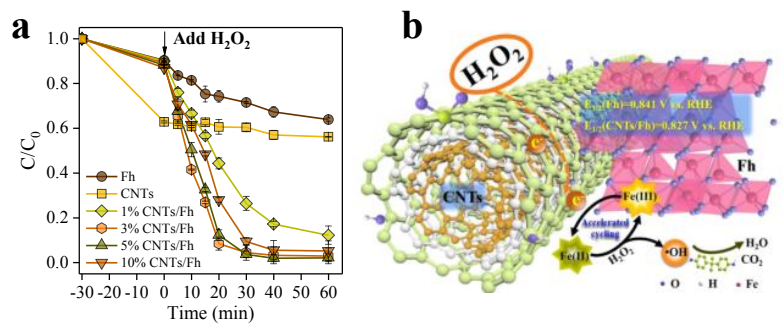

Fig.1 (a) Degradation kinetics for the degradation of BPA by as-prepared catalysts; (b) possible heterogeneous Fenton catalytic mechanism in the CNTs/Fh system.

[1] Hou et al. (2017) Environ. Sci. Technol. 51, 5118-5126. [2] Bolobajev et al. (2015) Chem. Eng. J. 281, 566-574. [3] Qin et al. (2018) Water Res. 137, 130-143. [4] Liu et al (2017) Appl. Catal. B: Environ. 206, 642-652. 